\title{
Organogold Chemistry: I Structure and Synthesis
}

\author{
R V Parish \\ Department of Chemistry, UMIST, Manchester, M60 1QD, UK
}

\begin{abstract}
Organogold chemistry is enjoying a resurgence of interest as useful applications, largely physical or medicinal, are being found. There is also a wide range of novel molecules, some with curious structures. This article reviews the structures and syntheses of recently discovered gold compounds. A later article will describe their reactions and applications.
\end{abstract}

Organogold derivatives have been known for almost 100 years. Many fascinating compounds and reactions have been discovered but, until recently, they have found little practical application. However, the last ten to fifteen years have seen the development of new materials with potential applications in non-linear optics, conjugated linear polymers (potential molecular wires), liquid crystals, chemical vapour deposition and anti-tumour agents (see Box 1). On the other hand, in marked contrast to the neighbouring noble metals, compounds of gold have been very little used in homogeneous catalysis (but see reference 1). This review attempts to update previous treatments (see, for

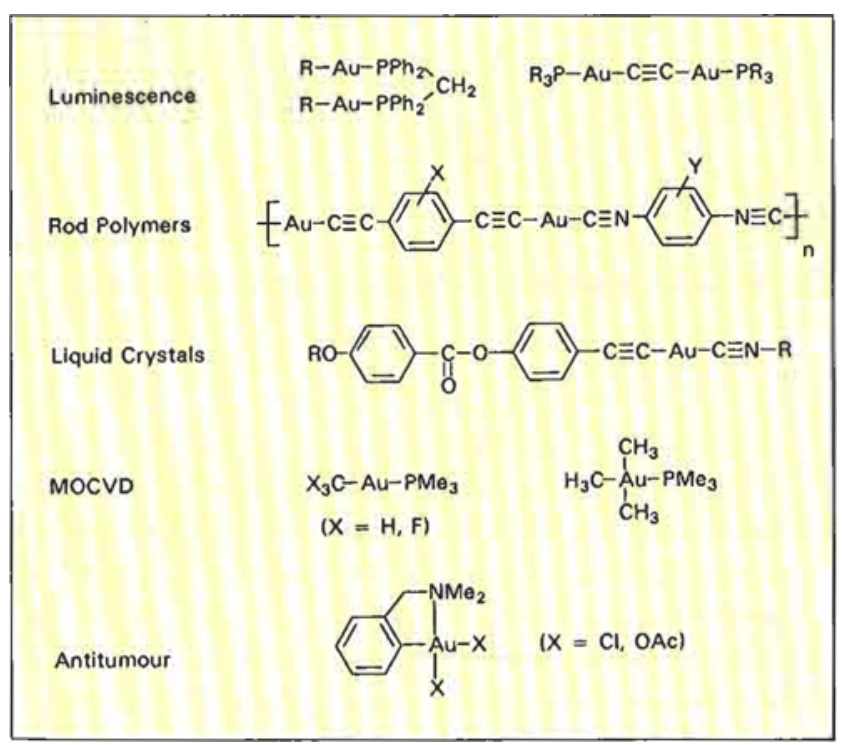

Box 1 Potential applications for gold compounds example, reference 2), and deals with the preparation, structures, properties and applications of some of the more interesting organogold systems; the examples given are drawn principally from those reported during the last ten years (a more comprehensive treatment is found in reference 3 ). The intention is to exemplify rather than to be comprehensive, and no mention at all is made of cluster compounds. Complexes in which carbonyl, cyano, or isonitrile ligands provide the only $\mathrm{Au}-\mathrm{C}$ bonds are also ignored. For convenience, the review is divided into two parts: this part deals with the wide variety of organic ligands now available and the structure and synthesis of the gold compounds derived from them; the second part treats the reactions and applications of these compounds.

\section{COMPOUNDS AND STRUCTURES}

Organic derivatives of gold are known for both of the common oxidation states, +1 and +3 , and there is an increasing number of gold(II) derivatives. The normal and predominant coordination numbers of gold are two for gold(I) and four for gold(III); as is common in this part of the Periodic Table, this gives stable configurations with 14 and 16 electrons respectively.

Homoleptic compounds $\mathrm{AuR}$ or $\mathrm{AuR}_{3}$ are therefore electron deficient and are unstable and highly reactive. This is true even though they achieve the 'normal' coordination number through polymerization via bridging alkyl or aryl groups and three-centre twoelectron bonds (see below). The principal examples of 


\begin{tabular}{|c|c|c|c|c|c|}
\hline \multicolumn{2}{|c|}{ Gold(I) } & \multicolumn{3}{|c|}{ Gold(III) } & \multirow[b]{2}{*}{$\mathrm{AuR}_{4}^{-}$} \\
\hline $\begin{array}{l}\operatorname{AuR}(L) \\
\operatorname{AuR}(X)\end{array}$ & $\mathrm{AuR}_{2}{ }^{-}$ & $\begin{array}{l}\operatorname{AuRX}_{2} L^{-} \\
\text {AuRX }_{3}^{-}\end{array}$ & $\begin{array}{l}\operatorname{AuR}_{2}(\mathrm{X}) \mathrm{L} \\
\mathrm{AuR}_{2} \mathrm{X}_{2}{ }^{-}\end{array}$ & $\begin{array}{l}\operatorname{AuR}_{3} \mathrm{~L} \\
\mathrm{AuR}_{3} \mathrm{X}-\end{array}$ & \\
\hline
\end{tabular}

Box 2 The possible stoichiometries ( $L=$ neutral ligand; $X=$ anionic ligand; $R=$ organic group)

stable compounds of empirical formula AuR are those in which the R-groups carry a functionality which allows polymerization by coordination to neighbouring gold atoms (eg $[\mathrm{AuC} \equiv \mathrm{CR}]_{\mathrm{n}}$ ). Compounds formulated originally as ' $\mathrm{AuR}_{3}$ ' or ' $\mathrm{AuR}_{3}\left(\mathrm{OEt}_{2}\right)$ ' are probably $\mathrm{Li}\left[\mathrm{AuR}_{3} \mathrm{Br}\right]\left(e g \mathrm{R}=\mathrm{CH}_{3}, \mathrm{C}_{6} \mathrm{~F}_{5}\right)$ (4).

Provided additional ligands are present to make up the coordination number, compounds of all possible stoichiometries are known, with one or two R-groups bonded to gold(I) and from one to four to gold(III) (Box 2). The structures of these compounds are as expected, linear and square planar; where appropriate, geometrical isomers can usually be obtained. In effect, the R-groups are carbanions acting as conventional, mononegative, two-electron ligands. Being amongst the softest ligands known*, they transfer much electron density to the gold atom; this is demonstrated, for instance, by Mössbauer spectroscopic data $(5,6)$, and they exert a high trans-influence. Compounds in which two R-groups are mutually trans are therefore generally of lower stability, and other soft ligands usually adopt positions cis to the R-group. For the same reason, $\left[A u R_{2}\right]^{-}$and $\left[A_{u} R_{4}\right]^{-}$are highly reactive. In all cases, derivatives of the harder perfluoro-organic groups $-\mathrm{CF}_{3}$ and $-\mathrm{C}_{6} \mathrm{~F}_{5}$ show considerably greater stability.

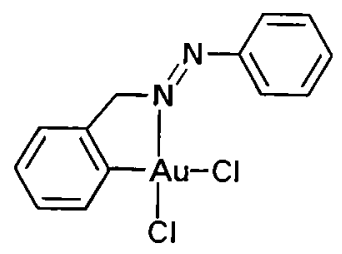

I<smiles>BrCC1c2ccccc2P(Br)C1(Br)Br</smiles>

III<smiles></smiles>

II<smiles>[3H]C[C@@]1(Cl)c2c3cccc2[C@]1(Cl)N(C)C3</smiles>

IV

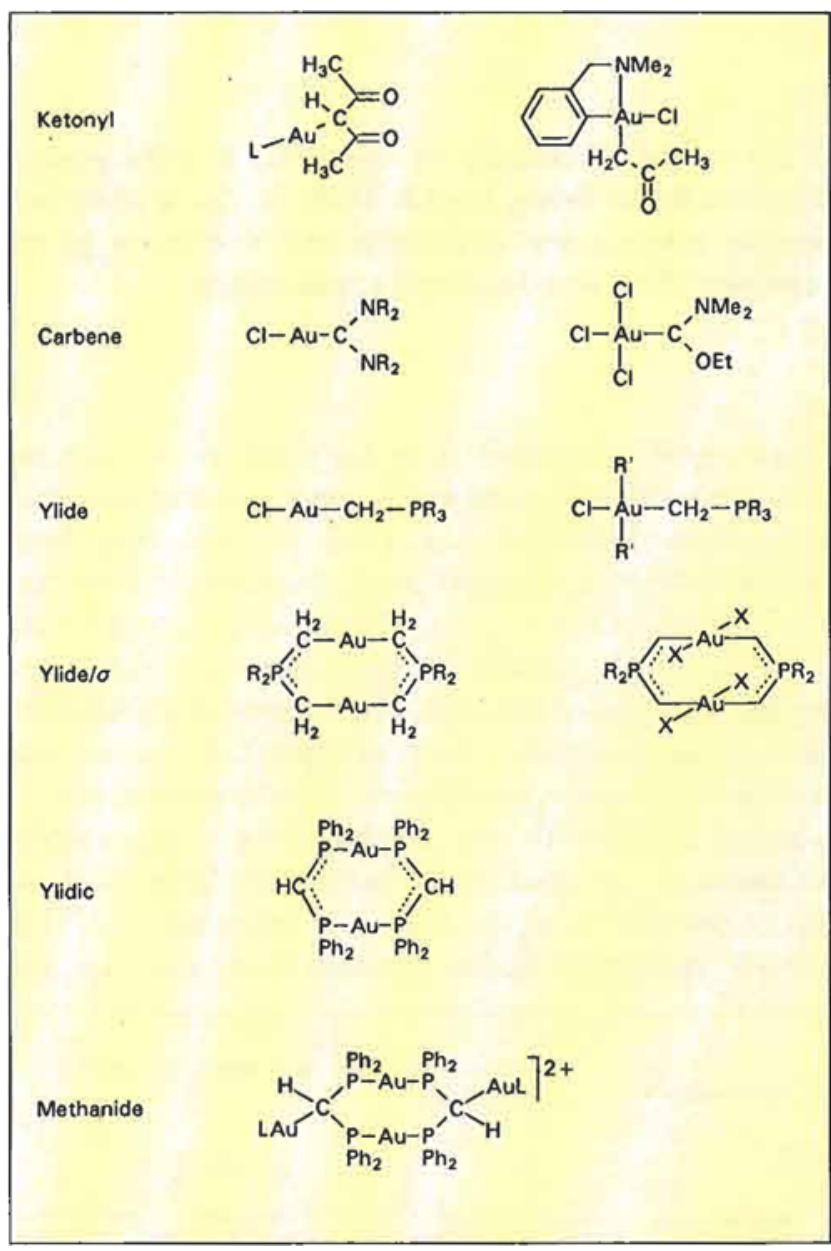

Box 3 Gold compounds with less conventional ligand systems 
<smiles>C1CCC[Pb]CCC1</smiles>

V<smiles>PC1=CC=CP(P2C=CC=PN2)C=P1</smiles>

VII

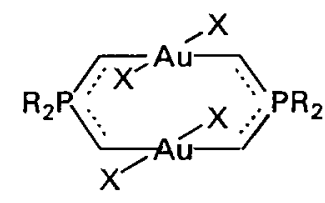

VI

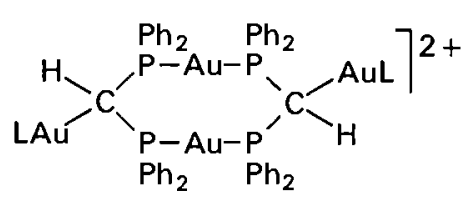

VIII
$\sigma$-Bonded organic ligands can be of all common types: alkyl, aryl, vinylic, acetylenic. The aryl derivatives in particular lend themselves to the formation of chelates when suitable substituents are present; naturally, the stereochemistry required means that these are limited to gold(III); examples are shown as I-IV (7-10).

Considerable attention has also been given to the synthesis of derivatives containing less conventional ketonyl, diketonyl, carbene, or ylide ligands; examples are given in Box 3 (typical references: 11-19). The distinction between the different types is not always obvious, and more than one can occur in the same molecule. A carbene may be considered, formally at least, as a neutral divalent carbon ligand, : $\mathrm{CY}_{2}$, where $\mathrm{Y}$ is often an alkoxy or amido group. The most common ylide ligands are effectively deprotonated phosphonium cations, eg $: \mathrm{CH}_{2} \mathrm{PPh}_{3}$ (derived from the methyltriphenylphosphonium cation, $\mathrm{CH}_{3} \mathrm{Ph}_{3} \mathrm{P}^{+}$), therefore also neutral. The dimethyldiphenylphosphonium cation can undergo two deprotonation stages to give : $\mathrm{CH}_{2} \mathrm{PPh}_{2} \mathrm{CH}_{2}^{-}$, which can act simultaneously as a conventional $\sigma$ bonded ligand and as an ylide; however, the negative charge is delocalized, and this ligand forms symmetrical bridges: two such ligands bind to two gold atoms forming an eight-membered ring system ( $\mathbf{V}$, VI). The dppm ligand, $\mathrm{Ph}_{2} \mathrm{PCH}_{2} \mathrm{PPh}_{2}$, forms a similar cyclic bis-gold(I) complex which can be deprotonated to give VII. Although ylidic, this complex does not

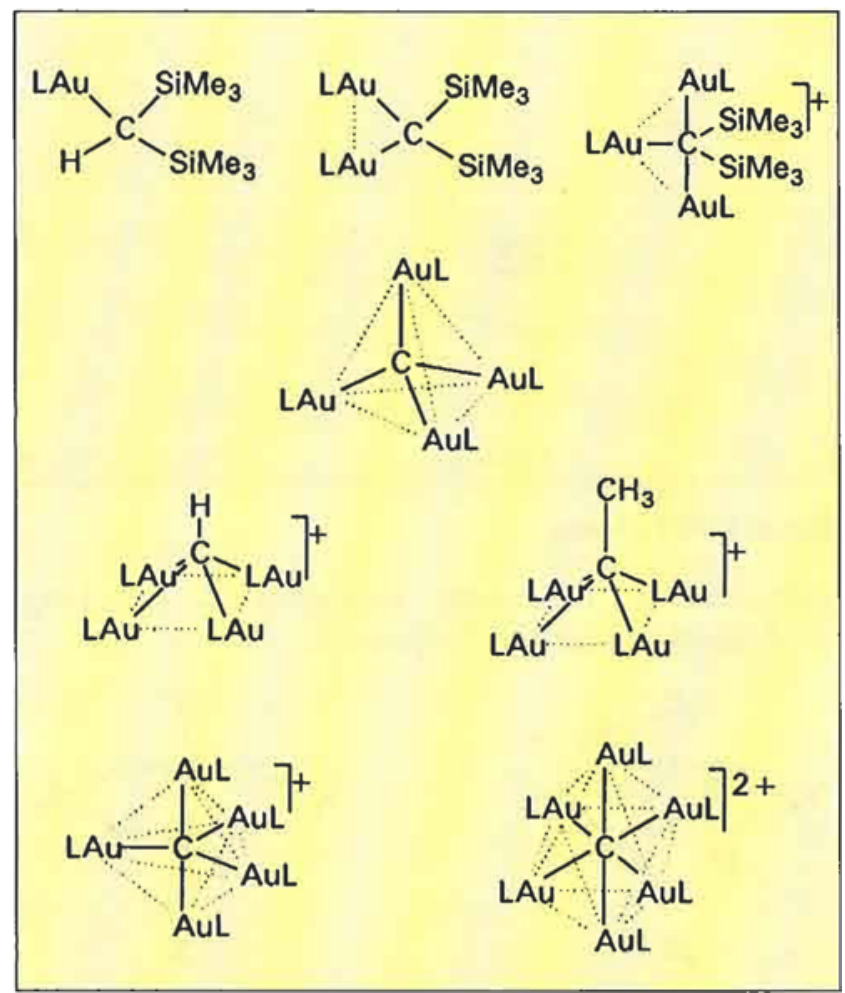

Box 5 Examples of carbon-centred and hypervalent gold compounds

contain gold-carbon bonds. It can, however, use the residual electron density on the bridging carbon atom to bind extra gold atoms (VIII); to distinguish complexes of this type from conventional $\sigma$-bonded organogold compounds, they are often called methanide complexes. Despite the unconventionality of some of these organic ligands, and the curiosity and complexity of some of the structures (Box 4, references 20-23), the stereochemistry at gold is highly normal.

The cyclic digold(I) ylide complexes are readily oxidized to give gold(III) complexes with conventional square planar $\mathrm{AuC}_{2} \mathrm{X}_{2}$ coordination but retaining the ring structure, VI, IX (24). With a single molar equivalent of halogen, gold(II) derivatives $(\mathrm{eg} \mathbf{X})$ are obtained (25-26). Although the gold atoms now formally have a $d^{9}$ configuration, the complexes are all diamagnetic; the coordination is square planar and includes a short bond to the second gold atom. This
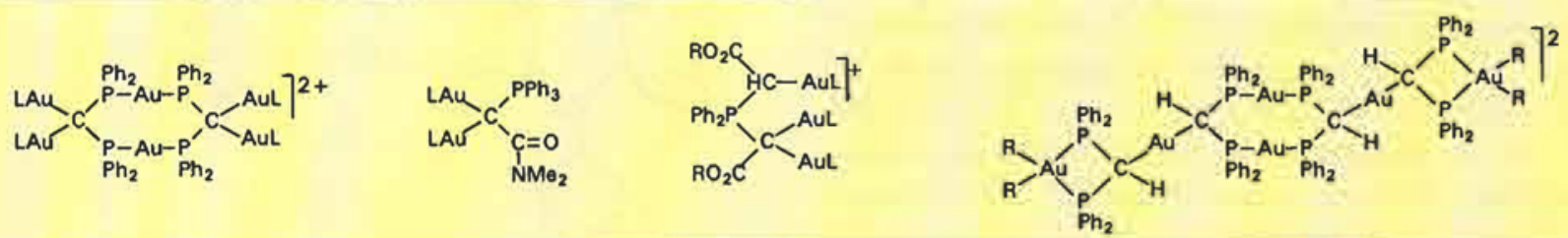

Box 4 Some 'exotic' ylidic and methanidic structures 


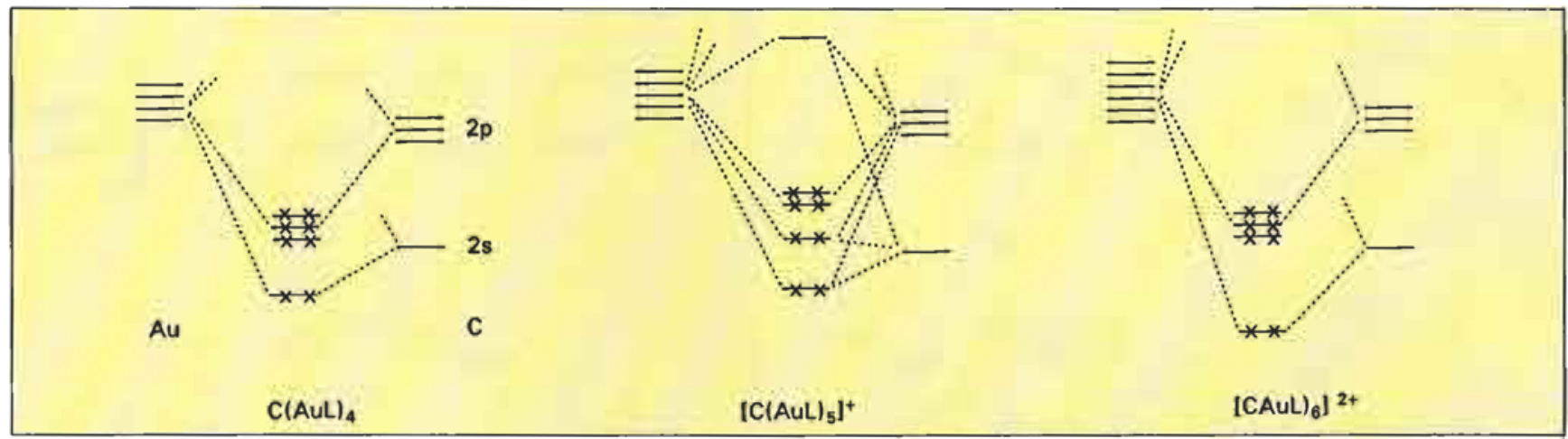

\section{Figure $1 M O$ schemes}

behaviour is, of course, analogous to the longestablished mercury(I) compounds.

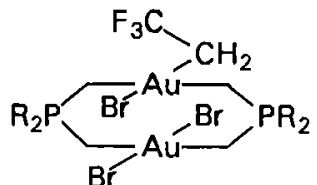

LX

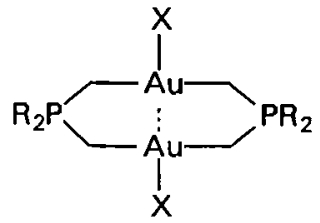

$\mathbf{X}$
In recent years a series of compounds has been discovered in which carbon atoms are $\sigma$-bonded to one to six $\mathrm{Au}^{\mathrm{I}} \mathrm{L}$ units, where $\mathrm{L}$ is a tertiary phosphine (Box 5 - references 27-31). In those involving fourcoordinate carbon, the structures are basically tetrahedral but the Au-C-Au angles are often smaller than the tetrahedral angle rather than larger as might have been expected on steric grounds. Even more curiously, the coordination number of the carbon atom increases readily above four, to five and even six; $\mathrm{C}(\mathrm{AuL})_{4}$ can be obtained only when $\mathrm{L}$ is a bulky ligand, such as $\mathrm{P}\left(\mathrm{C}_{6} \mathrm{H}_{11}\right)_{3}$. It should also be mentioned that analogous 'hypervalent' compounds are known with central atoms other than carbon (eg boron, oxygen, nitrogen, phosphorus, arsenic).

Satisfactory molecular orbital schemes may be constructed, in which the available valence electrons just fill the bonding molecular orbitals (Figure 1). The driving force for the formation of these remarkable compounds is the tendency for gold atoms to attract each other and for weak Au...Au bonding interactions to stabilize the compounds. Such interactions appear in a wide range of compounds $(32,33)$, and are estimated to have a strength comparable to hydrogen-bonds, ca $30 \mathrm{~kJ} \mathrm{~mol}^{-1}$. This effect has been named 'aurophilicity' (31), and is thought to be due to relativistic effects arising from the high nuclear charge (33 and references therein). Under its influence, electrons are accelerated to velocities comparable to that of light and they

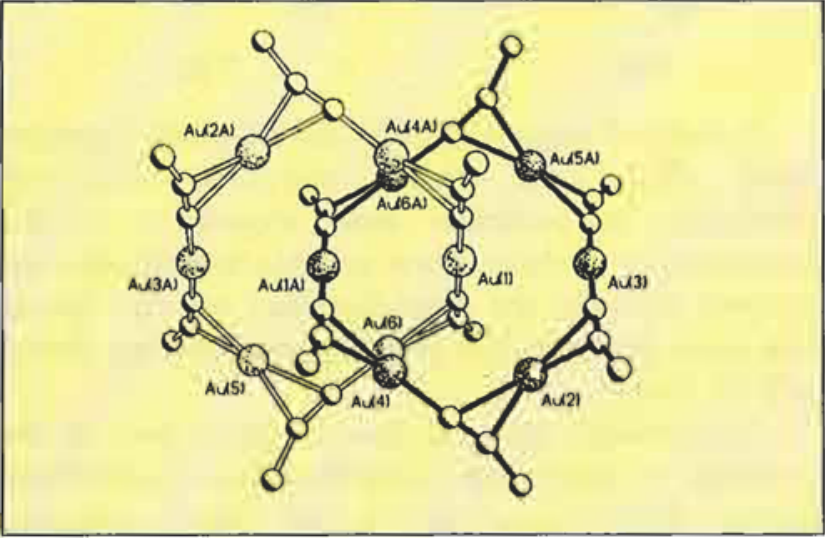

Figure 2 The molecular structure of $\left[A u C \equiv C B u^{l}\right]_{n}$ (Reprinted with permission from reference 37$)$.

experience an increase of mass. This affects their energies and, for the valence shell, allows much more orbital mixing than would otherwise be expected. These effects operate for all heavy atoms, but just happen to have a maximum at gold.

Other electron-deficient gold(I) compounds are best exemplified by $\mathrm{Au}_{2} \mathrm{Zn}_{2} \mathrm{Ph}_{6}$, for which structure $\mathbf{X I}$ has been proposed (34). This type of bridging has been confirmed in the ferrocene derivative XII, $\left(\mathrm{C}_{5} \mathrm{H}_{5}\right) \mathrm{Fe}\left[\mathrm{C}_{5} \mathrm{H}_{4}\left(\mathrm{AuPPh}_{3}\right)_{2}\right]^{+}$(35). The well-established (36) gold(I) alkynyl, $\left[\mathrm{Au}\left(\mathrm{C} \equiv \mathrm{CBu}^{\mathrm{l}}\right)\right]_{\mathrm{n}}$, was for a long
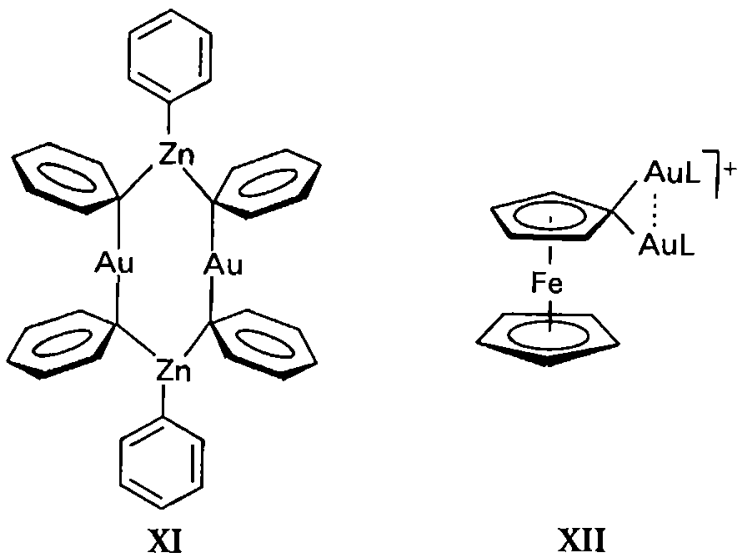

XII 
<smiles>[R]c1cc(C)c(O)c(Cc2cc([2H])cc(C)c2O)c1</smiles>

XIII

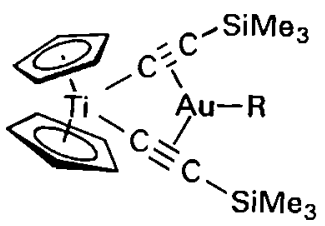

XIV

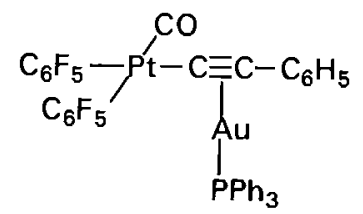

XV

time assumed to have a tetrameric square structure $(\mathrm{n}=$ 4), which would allow the triple bond to occupy the second coordination site at an adjacent gold atom, and thus remove the electron deficiency. This material has recently been crystallized and found (37) to have a much more fascinating, complicated structure involving all possible bonding situations: one gold atom has two $\sigma$-bonded alkynyl groups, one is $\pi$-bonded to two triple bonds, and a third has one $\sigma$ - and one $\pi$ - bond. Two of each of these units are bound together in a ring in which the gold atoms form a flat regular hexagon, and two rings are interlaced (see Figure 2). A similar mix of $\sigma$ - and $\pi$-bonded groups may occur in the gold(I) derivative of a propargyl-substituted calixarene, XIII, (38) and is also seen in XIV and XV $(39,40)$. Apart from the polymeric alkynyl derivatives, there is little evidence for $\pi$-bonded complexes. The highly unstable (explosive) cyclopentadienyl $\left[\mathrm{Au}\left(\mathrm{C}_{5} \mathrm{H}_{5}\right)\right]_{n}$ could polymerize either via three-centre bonds or by $\pi$ bonding analogous to that of the alkynyls, but nothing is known of its structure. In the substituted monomeric derivatives, such as $\mathrm{Ph}_{3} \mathrm{PAu}\left(\mathrm{C}_{5} \mathrm{H}_{5}\right)$, the cyclopentadienyl group is expected to be bound as a $\sigma$ bonded monohapto ligand ( $\eta^{1}$, two-electron donor). However, these molecules are fluxional on the NMR timescale and all carbon atoms are equivalent; as in other cases, the 1,2-shift may involve transient $\pi$ bonded intermediates (41).

\section{SYNTHESIS}

The most versatile and most often used method for the preparation of organogold compounds is the transmetallation reaction (2). Organolithium or Grignard reagents readily replace halide bound to gold. For gold(I), it is necessary to start with a complexed halide, $\mathrm{AuX}(\mathrm{L})$ (Equation 1), and to avoid an excess of the organometallic reagent unless it is intended to obtain

$$
\begin{aligned}
& \text { L-Au-X } \stackrel{\text { RMgX }}{\longrightarrow} \text { L-Au-R } \\
& \text { L-Au-R } \stackrel{\text { LiR }}{\longrightarrow} \text { LilAuR }_{2} \text { ] }
\end{aligned}
$$

the di-organoaurate(I) ion (Equation 2). Satisfactory Grignard reagents can be made from fluoro-aryls, but trifluoromethyl derivatives are best formed from $\mathrm{Cd}\left(\mathrm{CF}_{3}\right)_{2}$ (42). With gold(III) halides, the diorgano derivative $A_{u R} \mathrm{X}$ is the usual first product when starting from $\mathrm{Au}_{2} \mathrm{X}_{6}$ or $\mathrm{H}\left[\mathrm{AuX}_{4}\right]$. Again further reaction occurs readily with lithium reagents, to give $\left[\mathrm{AuR}_{3} \mathrm{X}\right]^{-}$or $\left[\mathrm{AuR}_{4}\right]^{-}$; this is also a convenient way of making mixed organic-ligand derivatives, which do not appear to undergo disproportionation. Monoorganogold(III) derivatives are usually obtained from organomercury reagents, and this is most commonly done with potential chelate ligands such as azobenzene or dimethylaminobenzylamine, eg to obtain I or $\mathbf{I V}(7,43,44)$.

$$
\begin{aligned}
& \overbrace{\mathrm{C}-\mathrm{Hg}-\mathrm{Cl}}^{\mathrm{N}} \frac{\left.\mathrm{Q}_{\mathrm{AuCl}}\right]}{\left.-\mathrm{Q}_{2} \mathrm{Hg}_{2} \mathrm{Cl}_{6}\right]} \mathrm{C}-\overbrace{\mathrm{Cl}}^{\mathrm{A} u}-\mathrm{Cl} \\
& \overbrace{\mathrm{C}-\mathrm{Hg}}^{-\mathrm{N}}-\mathrm{Cl} \frac{\left(\text { tht) } \mathrm{AuCl}_{3}\right.}{{ }_{-\mathrm{HgCl}_{2} \text { tht }}} \mathrm{C}-\overbrace{\mathrm{Cl}}^{\mathrm{Au}}-\mathrm{Cl}
\end{aligned}
$$

In the normal solvents (acetone or acetonitrile), the reactions represented by Equations 3 and $4(\mathrm{Q}=\mathrm{Na}$ or $\mathrm{Me}_{4} \mathrm{~N}$; tht = tetrahydrothiophene) are generally more efficient, but they appear to be finely balanced equilibria; it is sometimes necessary to add $\mathrm{Me}_{4} \mathrm{NCl}$ to encourage the precipitation of $\left(\mathrm{Me}_{4} \mathrm{~N}\right)_{2}\left[\mathrm{Hg}_{2} \mathrm{Cl}_{6}\right]$ (43). For some ligands (eg as in XVI, XVII) even this is not effective, but reaction will proceed if a more polar solvent is chosen, such as DMSO (10). It has been postulated that these reactions proceed via a bridged intermediate, XVIII, and that the solvent may inhibit the coordination of the $\mathrm{N}$-donor group to the mercury atom and allow it to bind to the gold (10). This is 
<smiles>CNS(=O)(=O)c1ccccc1[Al](Cl)(Cl)Cl</smiles>

XVI<smiles>[R]N(Cc1ccccc1Cl)[Ge](Cl)(Cl)Cl</smiles>

XVIII<smiles></smiles>

XX<smiles>O=C1N[Al](Cl)(Cl)c2ccccc21</smiles>

XVII<smiles></smiles>

XIX<smiles></smiles>

XXI

consistent with the failure of the lithium derivatives of these and similar ligands to react with $\left[\mathrm{AuCl}_{4}\right]^{-}$(43); presumably the organolithium is chelated, again discouraging the formation of the Au-N bond.

Solvent effects are also important in direct auration reactions of aromatic systems by gold(III) halides. The first arylgold derivative, $\left[\mathrm{AuPhCl}_{2}\right]_{2}$, reported in 1931, was obtained by direct reaction between benzene and $\mathrm{Au}_{2} \mathrm{Cl}_{6}$ (45). Alkyl benzenes would also react but not benzenes with potentially coordinating substituents; for instance, azobenzene gave XIX. More recently it<smiles></smiles>

XXII<smiles></smiles>

XXIII<smiles>CCCCC1C(C)=C(C)C(=O)C1[Al]C1=C(C)C(=O)CC1</smiles>

XXIV

was found that some of these adducts will undergo an ortho-metallation reaction, such as the transformation of XX into XXI (46). This is effected by refluxing the adduct in aqueous acetonitrile (3:1), and similar reactions have been used recently to prepare a range of $\mathrm{C}, \mathrm{N}$-bonded gold(III) chelates containing sixmembered rings such as XXII, including one in which an alkyl carbon atom has been metallated (XXIII) (47). Although it has not been commented on, the role of the solvent must be critical here, in allowing the escape or, more probably, the solvation of the liberated $\mathrm{HCl}$.

A versatile method involving exchange of organic groups has been developed. Reaction of $\left[\mathrm{AuCl}_{2}\right]^{-}$with thallium(I) acerylacetonate produces $\left[\mathrm{Au}(\mathrm{acac})_{2}\right]^{-}$ (XXIV). This complex reacts with organic molecules having a moderately acidic hydrogen (HR) to liberate acetylacetone and form the corresponding $\left[\mathrm{AuR}_{2}\right]^{-}$(48). For instance, the ethynyl complex $\left[\mathrm{Au}(\mathrm{C} \equiv \mathrm{CH})_{2}\right]^{-}$is readily made this way (49); as the $\left[\mathrm{N}\left(\mathrm{PPh}_{3}\right)_{2}\right]^{+}$salt, this anion is much more stable than previously reported (50). Simple gold(I) alkynyls are still made by the traditional method (36) which was effectively the reaction of $\left[\mathrm{AuBr}_{2}\right]^{-}$with $\mathrm{HC} \equiv \mathrm{CR}$ in the presence of sodium acetate. Similar proton-elimination reactions are used to prepare the substituted derivatives $\mathrm{LAuC} \equiv \mathrm{CR}$ from LAuCl (see, for example, references 51-55); alternatively, $[\mathrm{AuC} \equiv \mathrm{CR})]_{\mathrm{n}}$ is treated with the ligand (56).<smiles>C=Cc1ccccc1P(c1ccccc1)c1ccccc1</smiles>

XXV<smiles>C=Cc1ccccc1P(Br)c1ccccc1</smiles>

XXVI
The unusual compound III is prepared by bromination of a gold(I) derivative of styryldiphenylphosphine (XXV). Oxidation occurs rapidly at the gold atom to give XXVI which

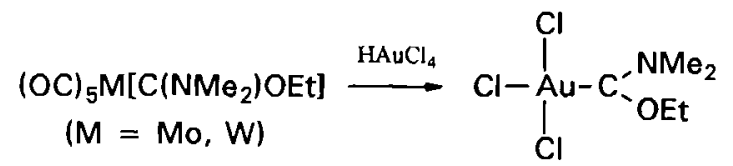

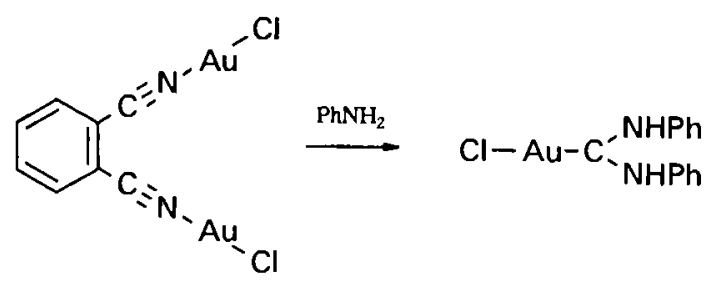




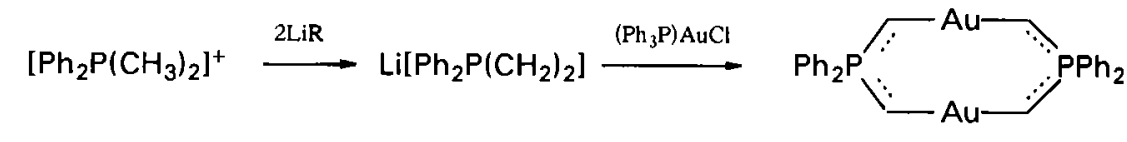

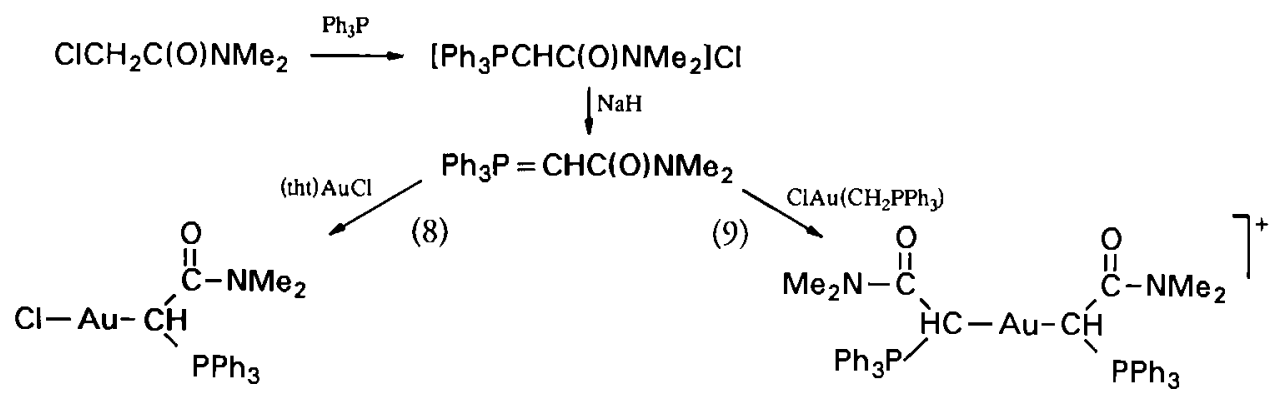

undergoes slow rearrangement to III $(9,57)$. Analogous reactions occur with the corresponding allyl-substituted phosphine (9).

Carbene complexes can be obtained by transmetallation, involving metal carbonyl derivatives (Equation 5) (14) or by nucleophilic attack on an isonitrile (Equation 6) (13). Ylides are usually obtained by deprotonation of a methyl phosphonium salt, using butyl lithium or sodium hydride. They are strong ligands and readily replace halides, or other weakly bound ligands from gold(I) complexes (Equations 7,8) $(22,48)$. In some cases a ligand already bound may act as the deprotonating agent (Equations 9-11) (18, 48). A range of methanide complexes can be obtained by making use of the basicity of an ylide carbon atom (Equations 12-15) $(18,58)$.

Finally, many of the hypervalent compounds are made by an ingenious reaction in which a dimethoxyboryl compound undergoes displacement of the $\mathrm{B}(\mathrm{OMe})_{2}$ group by an $\mathrm{AuL}^{+}$group and simultaneously becomes transformed into a $\mathrm{BF}_{4}-$ anion by the addition of $\mathrm{CsF}$ (in THF solution) (Equations $16,17)(25,26)$.<smiles>ClC(Cl)(Cl)Cc1ccccc1</smiles>

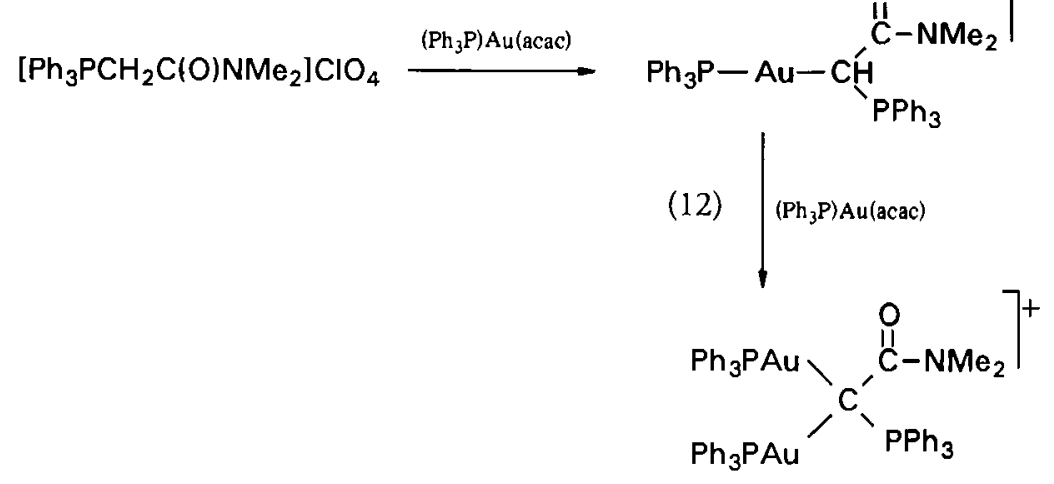




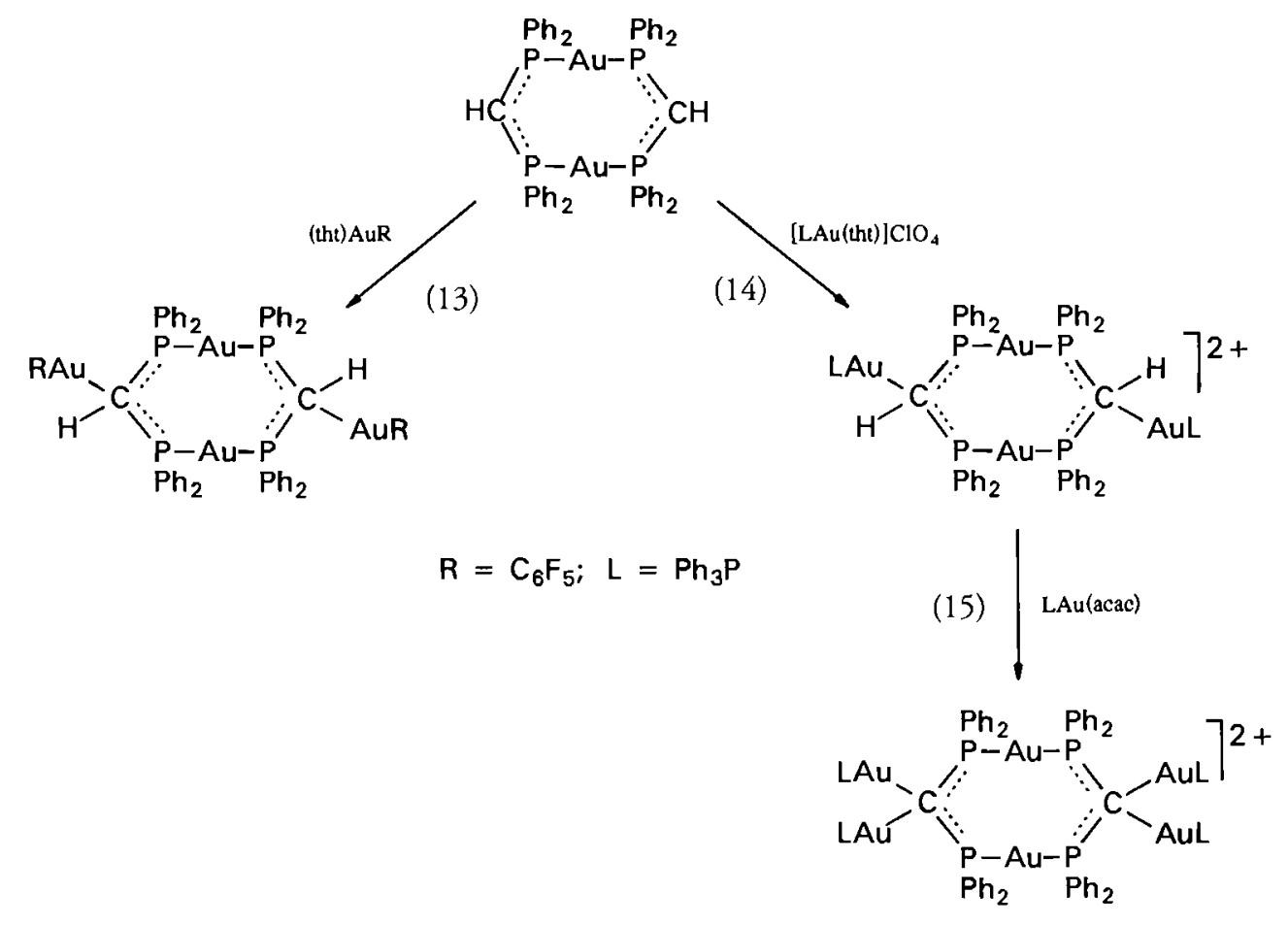

\section{CONCLUSIONS}

This survey shows that, despite the enormous variety of types of organogold compound now known, some apparently rather exotic, their coordination numbers and stereochemistries obey simple rules: gold(I) is two-coordinate and linear, and gold(III) is four coordinate and square planar. While other structures are known (a few three- and four- coordinate gold(I) complexes, a very small number of five coordinate gold(III) complexes) they do not appear in organogold chemistry except perhaps as reaction intermediates.

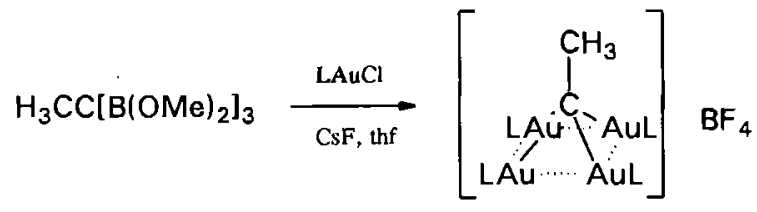

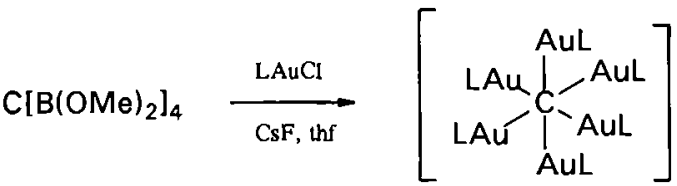
$\left(\mathrm{BF}_{4}\right)_{2}$
An increasing number of applications for gold compounds can be envisaged, and many of these are based on the organogolds; these will be discussed in a second article. These applications depend on the ways in which organogold compounds react, and these reactions will also be surveyed.

\section{ABOUT THE AUTHOR}

Dick Parish is Reader in Chemistry at UMIST and has a long-standing interest in the chemistry of gold, particularly of compounds with actual or potential medicinal interest, and in the application of Mössbauer spectroscopy to coordination chemistry, including that of gold.

\section{REFERENCES}

1 S. Komiya, T. Sone, Y. Usui, M. Hirano and A. Fukuoka, Gold Bull., 1996, 29, 131

2 R.J. Puddephatt in Comprehensive Organometallic Chemistry, (ed. G. Wilkinson, F.G.A. Stone, and E.W. Abel), Pergamon, Oxford, 1982; Gmelin's Handbuch der Anorganischen Chemie: Goldorganische Verbindungen, (ed. $\mathrm{H}$. Schmidbaur), Springer Verlag, Berlin, 1980

3 A. Grohmann, H. Schmidbaur, Comprehensive 
Organometallic Chemistry II, (ed. J. Wardell, E.W. Abel, F.G.A. Stone and G. Wilkinson), Pergamon, Oxford, 1995

4 R. Usón, A. Laguna and P. Brun, J. Organomet. Chem., 1979, 182, 449; R. Usón, A. Laguna and J. Vicente, J. Organomet. Chem., 1979, 131, 471

5 R.V. Parish, Gold Bull., 1982, 15, 51; 'Mössbauer Spectroscopy Applied to Inorganic Chemistry', Ed. J.G. Long, Plenum Press, New York, Vol 1, 1984, p. 589

6 F. Bonati, A. Burin, B.R. Pietroni, E. Torregiani, S. Calogero and F.E. Wagner, $J$. Organomet.Chem., 1991, 408, 125; G. Banditelli, F. Bonati, S. Calogero, G. Valle, F.E. Wagner and R. Wordel, Organometallics, 1986, 5, 1346

7 J. Vicente, M.T. Chichote and M.D. Bermúdez, Inorg. Chim. Acta, 1982, 63, 35

8 R.V. Parish and J.P. Wright, unpublished observations

9 M.A. Bennett, K. Hoskins, W.R. Kneen, R.S. Nyholm, R. Mason, P.B. Hitchcock, and G.B. Robertson and A.D.C. Towl, J. Am. Chem. Soc., 1971, 93, 4592; M.A. Bennett, J. Organomet. Chem., 1986, 300, 7

10 P.A. Bonnardel, R.V. Parish and R.G. Pritchard, J. Chem. Soc., Dalton Trans., 1996, 3185

11 D. Gibson, B.F.G. Johnson and J. Lewis, J. Chem. Soc., 1970, 367

12 J. Vicente, M.D. Bermúdez, M.P. Carillo and P.G. Jones, J. Chem. Soc., Dalton Trans., 1992, 1975

13 W.P. Fehlhammer and W. Finck, J. Organomet. Chem., 1991, 414, 261

14 E.O. Fischer and M. Böck, J. Organomet. Chem., 1988, 287, 279; E.O. Fischer, M. Böck and R. Aumann, Chem. Ber. 1983, 116, 3618

15 R. Usón, A. Laguna, M. Laguna, M.C. Gimeno, A. de Pablo, P.G. Jones, K. Mayer-Bäse, and C.F. Erdbrügger, J. Organomet. Chem., 1987, 336, 461

16 H. Schmidbaur, J.R. Mandl, A. WohllebenHammer and A. Fügner, Z. Naturforsch., 1978, 33B, 1325

17 H. Schmidbaur and R. Franke, Angew. Chem., Int. Ed Engl., 1973, 12, 416

18 R. Usón, A. Laguna, M. Laguna and M.C. Gimeno, J. Chem. Soc., Dalton Trans., 1989, 1883

19 R. Usón, A. Laguna, M. Laguna, A. Usón and M.C. Gimeno, J. Chem., Soc., Dalton Trans., 1988,710

20 E.J. Fernández, M.C. Gimeno, P.G. Jones, A. Laguna, M. Laguna, and J.M. Lopez de
Luzuriaga, Angew. Chem., Int. Ed Engl., 1994, 33, 87

21 J. Vicente, M.T. Chichote, M.C. Lagunas and P.G. Jones, J. Chem. Soc., Dalton Trans., 1991, 2579

22 J. Vicente and M.Y. Chichote, I. Saura-Llamas, J. Chem. Soc., Dalton Trans., 1990, 1941

23 E.J. Fernández, M.C. Gimeno, P.G. Jones, A. Laguna, M. Laguna, J.M. López-de-Luzuriaga and M.A. Rodriguez, Chem. Ber, 1995, 128, 121

24 H.H. Murray, L.C. Porter, J.P. Fackler and R.G. Raptis, J. Chem. Soc., Dalton Trans., 1996, 2669; R.G. Raptis, J.P. Fackler, J.D. Basil and D.D. Dudis, Inorg. Chem., 1991, 30, 3072

25 J.D. Basil, H.H. Murray, J.P. Fackler, J. Tocher, A.M. Mazany, T.J. Delord, B.T. Bancroft, $H$. Knachel, D.S. Dudis and D.O. Marler, J. Am. Chem. Soc., 1985, 107, 6908; H.H. Murray, J.P. Fackler and B. Trczinska-Bancroft, Organometallics, 1985, 4, 1633

26 H. Schmidbaur and R. Franke, Inorg. Chim. Acta, 1975, 13, 85

27 S. Bommers, H. Beruda, N. Dufour, M. Paul, A. Schier and H. Schmidbaur, Chem. Ber., 1995, 128, 137

28 O. Steigelman and $H$. Schmidbaur, $Z$. Naturforsch., 1993, 47b, 1721

29 O. Steigelman, P. Bissinger and H. Schmidbaur, Z. Naturforsch., 1992, 48b, 72

30 F. Scherbaum, A. Grohmann, G. Müller and H. Schmidbaur, Angew Chem., Int. Ed. Engl., 1989, 28, 463

31 F. Scherbaum, A. Grohmann, B. Huber, C. Krüger and H. Schmidbaur, Angew Chem., Int. Ed. Engl., 1988, 27, 1544

32 P.G. Jones, Gold Bull., 1981, 14, 102, 159; 1983, 16, 114; 1986, 19, 46

33 H. Schmidbaur, Gold Bull., 1990, 23, 11

34 P.W.J. de Graaf, J. Boersma and G.J.M. van der Kerk, J. Organomet. Chem., 1977, 127, 391

35 A.N. Nesmeyanov, E.G. Perevalova, K.I. Grandberg and D.A. Lemonvskii, Izv. Akad. Nauk SSSR, Ser. Khim., 1974, 1124

36 G.E. Coates and C. Parkin, J. Chem. Soc., 1962, 3220

37 D.M.P. Mingos, J. Yau, S. Menzer and D.J. Williams, Angew Chem., Int. Ed Engl., 1995, 34, 1894

38 W. Xu, J.J. Vittal and R.J. Puddephatt, Can.J. Chem., 1996, 74, 766

39 H. Lang, K. Köhler and L.Z. Solnai, J. Chem. Soc., Chem. Commun., 1996, 2043 
40 J.R. Berenguer, J. Forniés, E. Lalinde, F. Martinez, E. Urriolabeitia and A.J. Welch, J. Chem. Soc., Dalton Trans., 1994, 1291

41 C.H. Campbell and M.L.H. Green, J. Chem. Soc., 1971, 3283

42 H.K. Nair and J.A. Morrison, J. Organomet. Chem., 1989, 376, 149

43 J. Vicente, M.T. Chichote and M.D. Bermúdez, J. Organomet. Chem., 1984, 268, 191

44 R.V. Parish, B.P. Howe, J.P. Wright, J. Mack, R.G. Pritchard, R.G. Buckley, A.M. Elsome and S.P. Fricker, Inorg, Chem., 1996, 35, 1659

45 M.S. Kharasch and H.S. Isbell, J. Am. Chem. Soc., 1931, 53, 2701, 3503

46 E.C. Constable and T.A. Leese, J. Organomet. Chem., 1989, 363, 419

47 M.A. Cinellu, A. Zucca, S. Stoccoro, G. Minghetti, M. Manassero and M. Sansoni, J. Chem. Soc., Dalton Trans., 1995, 2865; ibid, 1996,4217

48 J. Vicente, M.T. Chichote, I. Saura-Llamas and M.C. Lagunas, J. Chem. Soc., Chem. Commun., 1992,915
49 J. Vicente, M.T. Chichote and M-D. Abrisqueta, J. Chem. Soc., Dalton Trans., 1995, 497

50 R. Nast and U. Kirner, Z. Anorg. Allg. Chem., 1964, 330, 311

51 T.E. Müller, D.M.P. Mingos and D.J. Williams, J. Chem Soc., Chem. Comm., 1984, 1787

52 R.J. Cross, J. Chem. Soc, Dalton Trans., 1986, 411

53 D. Li, X. Hong, C.M. Che, W.C. Lo and S.M. Peng, J. Chem. Soc., Dalton Trans., 1993, 2929

54 M.J. Irwin, G. Jia, N.C. Payne and R.J. Puddephatt, Organometallics, 1996, 15, 51

55 G. Jia, N.C. Payne, J.J. Vittal and R.J Puddephatt, Organometallics, 1993, 12, 4771

56 H. Xiao, K-K. Cheung and C.M. Che, J. Chem. Soc., Dalton Trans., 1996, 3699

57 R.V. Parish and H. Sailes, unpublished observations

58 E.J. Fernández, M.C. Gimeno, P.G. Jones, A. Laguna, M. Laguna and J.M. López de Luzuriaga, J. Chem. Soc., Dalton Trans., 1992, 3365 